\title{
Mechanical response of a thermal micro-pile installed in stratified sedimentary soil
}

\author{
Brunella Casagrande ${ }^{1,{ }^{*}}$ Fernando Saboya ${ }^{1}$, Sergio Tibana ${ }^{1,}$ and John S. McCartney ${ }^{2}$ \\ ${ }^{1}$ Department of Civil Engineering, UENF, Av. Alberto Lamego 2000 - CCT, Campos dos Goytacazes, Rio de Janeiro \\ ${ }^{2}$ University of California San Diego, Department of Structural Engineering. La Jolla, CA, USA
}

\begin{abstract}
Data regarding the behavior of thermal piles in tropical countries is not as readily available as those in European or other temperate climate regions, where most applications are directed toward extracting heat from the subsurface. Similarly, a deep understanding of thermal piles constructed using the micropile technique has not been obtained. In micropiles, the installation process can disturb the surrounding soil, especially at the tip. This paper presents the results from a set of thermal response tests (TRT) performed on a $12 \mathrm{~m}$-long instrumented thermal micro-pile installed in a sedimentary tropical soil. Vibrating wire strain gauges were installed in order to assess the mechanical performance of the pile when subject to thermal loads. Results indicate that the temperature distribution with depth is far from being homogeneous through the entire length of the pile. The resulting induced strains are strongly dependent on the subsoil conditions.
\end{abstract}

\section{Introduction/Background}

While energy is essential to enable the socio-economic development of society, it represents one of the segments of society that has an adverse impact over the environment. According to the Global Carbon Budget (2018), carbon dioxide is responsible for $58.8 \%$ of the gases that contribute to the greenhouse effect. In developed countries geothermal energy has received remarkable attention as a largely untapped renewable resource that does not produce significant $\mathrm{CO}_{2}$ emissions during electricity generation [1]. Geothermal energy has advantages of other energy sources as it is available daily and in all seasons of the year [2]. In order to access geothermal energy in the shallow surface, energy piles are often used to exchange heat between a building and the ground through the principle of a ground-source heat pump (GSHP). Energy piles support buildings while acting as underground heat exchangers coupled with closed-loop, flexible, high-density polyethylene (HDPE) tubing within the reinforcing cage, through which a heat exchange fluid is circulated. The temperature of the fluid is controlled using the GSHP within the building to maintain thermal comfort $[3,4]$.

During heating and cooling cycles, thermal piles expand and contract changing the pile-soil interaction. In some cases, this may result in unwanted consequences, such as additional building settlement, tensile axial stresses, large compressive axial stresses or mobilization of limiting resistance on the pile shaft [5].

Thermal response tests (TRTs) are used to estimate the thermal properties of the energy pile and surrounding subsurface and are commonly performed on vertically- oriented geothermal heat exchangers that can be approximated using a line source [6]. TRTs also provide a means of assessing the soil-structure interaction mechanisms for a given soil deposit. A carrier fluid is circulated through a closed-loop pipe, which may be embedded within an energy pile or a borehole leading to heat transfer primarily by conduction [7]. Data from inlet and outlet temperature along with the fluid flow rate are acquired to understand the heat transfer rate into or from the subsurface.

Several studies have investigated the impacts of temperature changes on axial strain in the energy piles [4, 8-17]. It has been well established that changes in temperature along the energy pile generates deformations that can cause extra stresses depending on the restraint conditions which must be accounted in their design. Further, the effects of temperature change on the soil around the pile can increase the interface shear strength due to heating, which may be explained by thermal consolidation on clay soil. Further, the effects of the temperature change on the soil around the pile can increase the interface shear strength due to heating, which may be explained by thermal consolidation. Recent studies on laboratory tests [18] and on centrifuge modeling [19-22] have investigated this effect. For example, McCartney and Rosenberg (2011) concluded that foundations heated from 15 to $60^{\circ} \mathrm{C}$ and then loaded axially to failure experienced an increase in side shear resistance of $40 \%$ above that of baseline foundations tested at ambient temperature. Goode and McCartney (2015) performed additional testing that confirmed these trends, while Behbehani and McCartney (2020) found that these trends were due to an increase in effective stress

\footnotetext{
* Corresponding author: brunellacasagrandeb@gmail.com
} 
along the pile associated with thermally-induced drying away from the energy pile. Di Donna et al. (2016) observed an increase of the clay-pile interface shear strength due to heating. Although the cyclic thermal mechanism has been investigated through laboratory test and centrifuge modeling, it is not well understood and studied at field scale. This study presents a field investigation involving cyclic thermal response tests on an energy micropile.

\section{Soil Profile}

The energy pile investigated in this study is located in Campos dos Goytacazes on north of Rio de Janeiro state, Brazil on the margin of Paraiba River. The predominant soil is from the sedimentary Paraiba basin deposit. The area has a tropical weather climate with a winter dry season and is classified as "Aw" according to the Köppen and Geiger weather classification system. It has an annual average temperature of $24.1^{\circ} \mathrm{C}$ reaching a maximum of $26.7^{\circ} \mathrm{C}$ during the summer.

A site investigation was performed in July 2017 by Ferreira (2017), extending $12 \mathrm{~m}$ below the ground surface. The pile is located near the Paraiba river presenting an expressive ground water table fluctuation. At the site investigations the ground water table was at the depth of $6.5 \mathrm{~m}$. Exploration results from the borehole showed three prominent strata: sand, organic clay and fill.

The top layer is approximately $3.5 \mathrm{~m}$-thick and consists of fill. Beneath the fill is a $1.5 \mathrm{~m}$-thick silty-sand layer, followed by a $3 \mathrm{~m}$-thick layer of sand. An organic clay layer was encountered between depths of 8.5 and $10.8 \mathrm{~m}$, which is followed by a silty sand layer extending to the maximum depth explored. More detailed information on the soil profile can be found in Fig. 1.

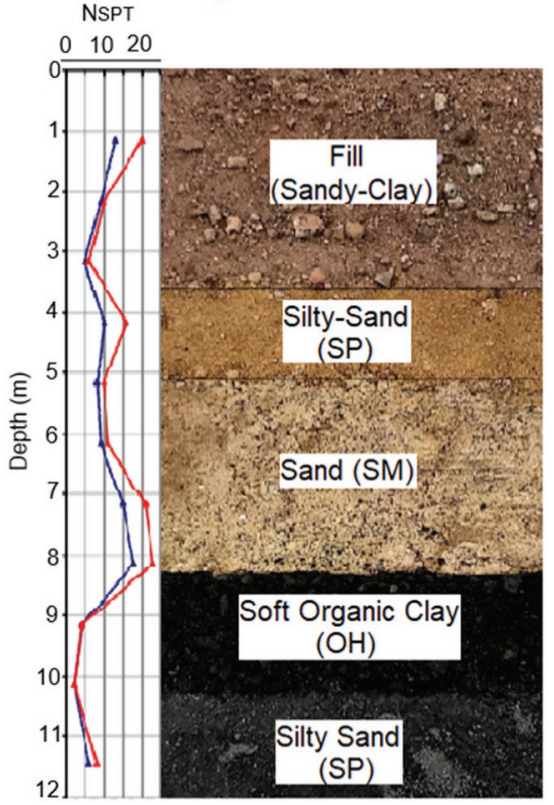

Fig. 1. Soil strata and standard penetration test (SPT) blow counts.

\section{Experimental Set up}

A cast-in-place $0.4-\mathrm{m}$ diameter energy micro-pile was installed in the sedimentary soil deposit to a depth of $12 \mathrm{~m}$. The concrete used in the pile had a tensile strength of $3.4 \mathrm{MPa}$ and a compressive strength of $29 \mathrm{MPa}$ measured from a diametric Brazilian test. The foundation contains a $9.5 \mathrm{~mm}$-diameter steel reinforcing cage configured in a triangular arrangement that extends the full length of the shaft. A $25 \mathrm{~mm}$-diameter heat exchange tubing composed of PEX-A monolayer was installed in the pile and placed in a "U" shape attached to the inside of the reinforced cage [23].

The energy pile was equipped with four Geokon model 4150 vibrating wire strain gauges attached to the reinforcing cage at different locations along the length of the pile which are shown in Fig. 2. The strain gauges were named as follows: A05 corresponds to a depth of $11.55 \mathrm{~m}$, A04 to $8.77 \mathrm{~m}, \mathrm{~A} 03$ to $6.1 \mathrm{~m}$, and A02 to $3.2 \mathrm{~m}$ (Fig. 2). The strain gages were also able to monitor the temperature using an embedded thermistor, so together they permit monitoring of the distribution of axial strain and temperature with depth during the heating process. The sensor cables were connected to a Geokon data acquisition system that permitted monitoring of the variations in temperature and strain over 10 minute intervals. In order to measure the inlet and outlet temperatures of the heat exchanger fluid on the foundation, pipe plug thermistors were installed in within the inlet and outlet of the heat exchange tubing.

In order to assess the mechanical performance of the pile when subject to thermal loads only no mechanical loading was imposed on the pile head. The final configuration of the test consists of a water pump, a flow meter, water heaters, and a thermally isolated water tank.

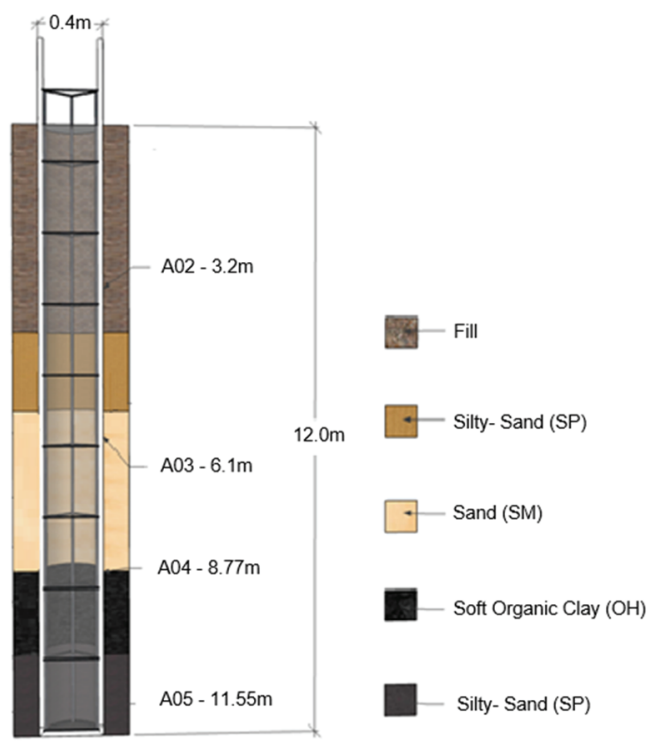

Fig. 2. Pile instrumentation scheme.

\section{Test Procedures}

Three TRTs were performed on the energy pile using different heat exchanger flow rates and heat transfer rates. 
In TRT\#1, a flow rate of $30.1 \mathrm{1} / \mathrm{min}$ was established while in TRT\#2 and TRT\#3 a flow rate of $19.71 / \mathrm{min}$ was established. These flow rates all correspond to a turbulent flow regime within the heat exchanger pipes to maximize heat transfer to through the pipe. The first two TRTs were executed with heat transfer rate of $1.2 \mathrm{~kW}$ while TRT\#3 was executed with a heat transfer rate of $2.4 \mathrm{~kW}$. Comparison of these tests permit an evaluation of the effect of a higher temperature gradient on the estimation of thermal properties and investigation of soil-structure interaction mechanisms. During the test, the inlet and outlet temperatures of the heat exchanger fluid were continuously monitored. The duration of the three TRTs were also different, where TRT\#1, TRT\#2 and TRT\#3 were conducted for 75,50 and 75 hours, respectively.

\section{Results}

The average temperature changes reached during TRT\#1, TRT\#2 and TRT\#3 were 25,23 and $40{ }^{\circ} \mathrm{C}$, respectively. The average temperature change was determined as the difference between the inlet and outlet temperatures after stabilization. The temperature versus depth profiles for each test are shown in Fig. 3a. The thermal axial strain versus depth profiles after application of appropriate thermal corrections are also plotted in Fig. 3b. Smaller thermal strains and temperatures are observed at a depth of $9 \mathrm{~m}$, possibly due the presence of a clay layer. Higher thermal strains are observed near the tip and head of the energy pile in all three TRTs, which can be attributed to the high degree of freedom of the pile. Specifically, the micro-pile was not connected to a superstructure so it is free to move upward. Further, the construction approach used in micro-piles leads to a of bottom boundary so it can be assumed that it is free to move downward.

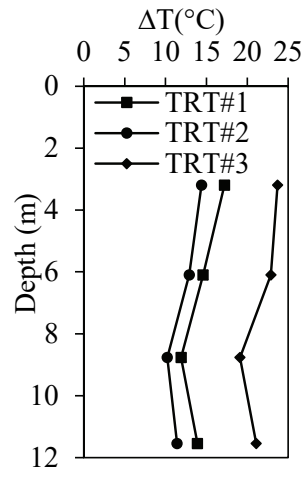

a)

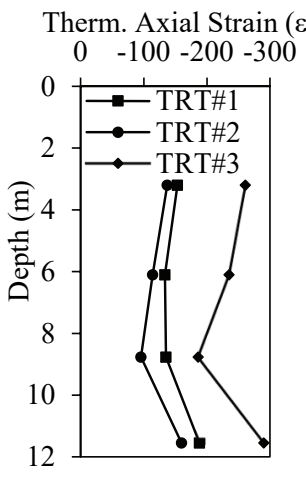

b)
Fig. 3. Profiles of: a Temperature change; b Thermal axial strain for the three Thermal Response Tests.

Thermal strain increments versus the change in temperature for each depth in each test are shown in

Fig. $4 a, 4 b$, and $4 c$, respectively. The slope of each curve allows estimation of the mobilized coefficient of thermal expansion. The profiles of this coefficient with depth are plotted in

Fig. 4d. A linear change in thermal axial strain with changes in temperature is noticed. A similar linear behavior was observed by Murphy et al. (2015). At a depth of $11.55 \mathrm{~m}$ the mobilized coefficient of thermal expansion reaches higher values (

Fig. 4d), it is coincident with the point of maximum strain located near the energy pile tip likely due to the lower amount of restraint provided by the deepest soil layer and the low-end bearing capacity expected for the construction technique used for the pile. Conversely, lower values of mobilized coefficient of thermal expansion are observed at the depth of 8-10 $\mathrm{m}$ (

Fig. 4d), agreeable with the location of the minimum thermal axial strain due to the clay layer.

The mobilized coefficient of thermal expansion for each depth in each test is plotted in Fig. 5. In all cases, the values of the mobilized coefficient of thermal expansion decreased after each subsequent heating cycle, reflecting smaller displacements throughout the pile with temperatures increments. This behavior can be associated with an increase in side shear resistance due to heating. It is possible that thermally induced drying led to an increase in restraint in these tests as observed by Behbehani and McCartney (2020) [22], but also could be related with thermal consolidation of the softer clay layer that results in greater restraint.
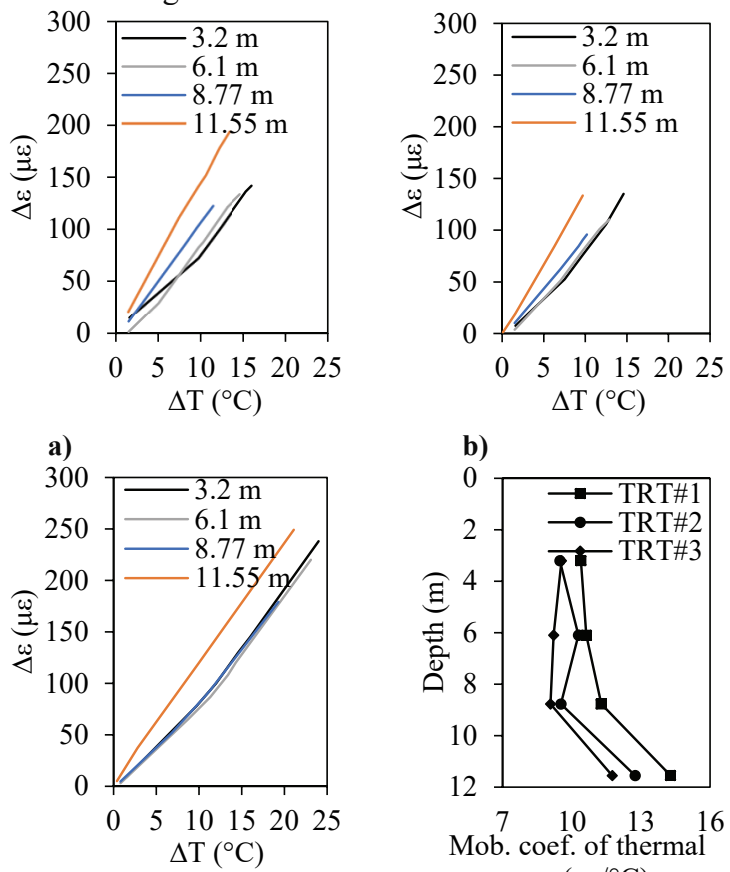

b)

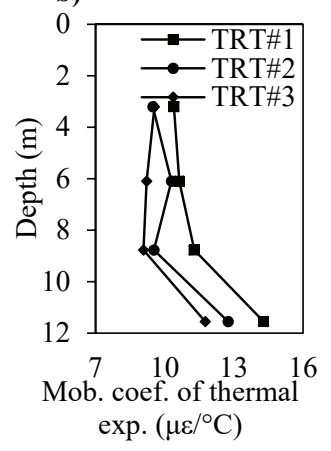

c)

d)

Fig. 4. Thermal axial strain with change in foundation temperature at each test: a TRT\#1; b TRT\#2; $\mathbf{c}$ TRT\#3; d mobilized coefficient of thermal expansion with depth for the three tests on the thermal pile. 

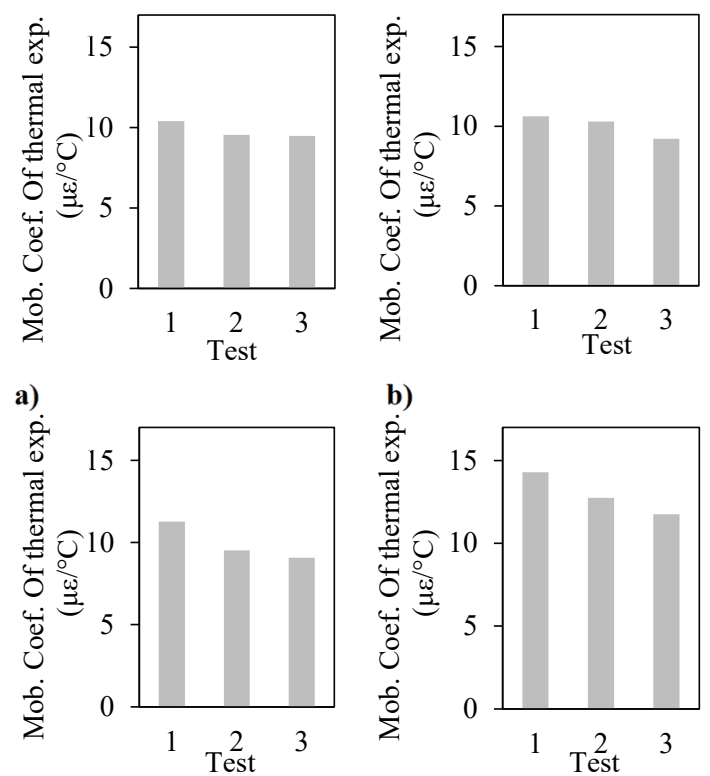

c)

d)

Fig. 5. Mobilized coefficients of thermal expansion for each depth in each test: a $3.2 \mathrm{~m} ; \mathbf{b} 8.7 \mathrm{~m} ; \mathbf{c} 6.21 \mathrm{~m}$ and $\mathbf{d} 11.55 \mathrm{~m}$

Analyzing the thermal strain increments versus the change in temperature for each test at the sensors located at a depth of $8.77 \mathrm{~m}$ on a clay layer (Fig. $6 \mathrm{c}$ ) and at the depth of $11.55 \mathrm{~m}$ (Fig. 6d) placed in a transition region between organic soft clay and clean sand, the slopes of the curves were observed to elevate with changes in temperature. This may reflect an increase in interface shear strength with increasing temperature for the subsequent heating cycles. This behavior has been reported by Di Donna et al. (2015), who tested the response of clay-concrete interfaces at different temperatures, after cyclic heating and cooling. Conversely, for the sensors located at the depths of $3.2 \mathrm{~m}$ on a fill layer composed mostly of sand (Fig. 6a) and on a sand layer at the depth of $6.1 \mathrm{~m}$ (Fig. 6b), heating led to a negligible change in ultimate capacity. This behavior was observed by Goode and McCartney (2015) during heating semi-floating energy piles in dry sand and by Di Donna et al. (2015) during application of temperature cycles to a sandy soil pile interface. Overall, the present work confirms that the effect of a temperature change on a semi-floating foundation cannot be neglected and can works towards increasing the interface soil shear strength in some soil layers [5]. These results also emphasize that different changes in soil-pile interface behavior may occur at different depths in sedimentary soil deposits like the one encountered in this study.
$\Delta \mathrm{T}\left({ }^{\circ} \mathrm{C}\right)$

2520151050

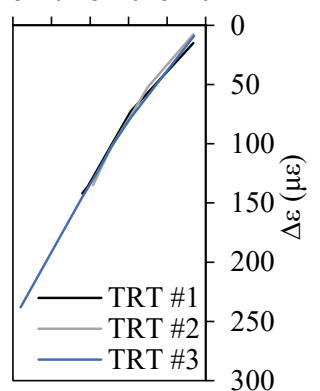

a)

$\Delta \mathrm{T}\left({ }^{\circ} \mathrm{C}\right)$

2520151050

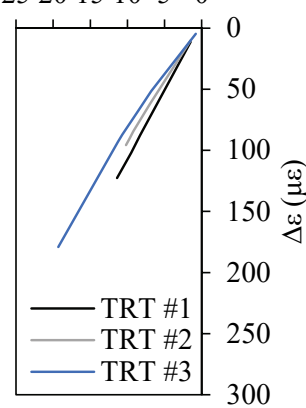

c)

Fig. 6. Increment of thermal strain versus increment of temperature for each test: a $3.2 \mathrm{~m} ; \mathbf{b} 8.77 \mathrm{~m} ; \mathbf{c} 6.1 \mathrm{~m}$ and d $11.55 \mathrm{~m}$.

\section{Conclusions}

Three TRTs were carried out in a cast-in-place energy pile with different heat exchanger fluid flow rates, heat transfer rates, and durations. Different temperature gradients were imposed due to these different testing conditions. Pile temperatures and thermal strains were monitored to understand the implication of the different testing conditions. Conclusions drawn from analysis of the experimental results are as follows:

- Smaller thermal strains and temperatures were observed in a clay layer encountered in the lower half of the energy pile.

- A linear change in thermal axial strain with changes in temperature was observed for all depths.

- The mobilized coefficient of thermal expansion reached the highest values in locations of maximum strain near the energy pile tip due to the lower restraint associated with the micro-pile construction technique. Conversely, the lowest values of the mobilized coefficient of thermal expansion were agreeable with the location of the minimum thermal axial strain.

- A decreasing on the mobilized coefficient of thermal expansion during each subsequent heating cycle were observed in a clay layer and can be associated with increase in side shear resistance due to cyclic heating. 


\section{References}

1. Pan S.-Y., Du M.A., Huang I.-T., Liu I.-H., Chang E.-E. \& Chiang P.-C. Strategies on implementation of waste-to-energy (WTE) supply chain for circular economy system: a review. Journal of Cleaner Production. 108: 409-421 (2015).

2. IEA http://www.iea.org/reports/world-energyoutlook-2011. (2011).

3. Chen D. and McCartney J.S. Parameters for load transfer analysis of energy piles in uniform nonplastic soils. ASCE International Journal of Geomechanics. 17(7): 04016159. (2016).

4. Faizal M., Bouazza, A., Haberfield, C., \& McCartney, J.S. Axial and radial thermal responses of a field-scale energy pile under monotonic and cyclic temperature changes,: Journal of Geotechnical and Geoenvironmental Engineering. 144(10): 04018072, (2018).

5. Amatya B.L., Soga, K., Bourne-Webb, P.J., Amis, T., and Laloui, L. Thermo-mechanical behaviour of energy piles Geotechnique. 62(6): 503-519 (2012).

6. Loveridge, F.A., Narsilio, G., Sanchez, M., and McCartney, J.S. (2019). Energy geostructures: a review of analysis approaches, in situ testing and model scale experiments. Geomechanics for Energy and the Environment. 22, 100173, 1-30.

7. Gehlin S. Thermal Response Test: Method Development and Evaluation. Doctoral Thesis. (2002).

8. Laloui L. Nuth, M., and Vulliet, L. Experimental and numerical investigations of the behaviour of a heat exchanger pile. International Journal for Numerical and Analytical Methods in Geomechanics. 30: 763781, (2006).

9. Brandl H. Energy foundations and other thermoactive ground structures Géotechnique. 56(2): 81126 (2006).

10. Bourne-Webb P.J. Amatya B., Soga K., Amis T., Davidson T., and Payne P. Energy pile test at Lambeth College, London: geotechnical and thermodynamic aspects of pile response to heat cycles Géotechnique. 59(3): 237-248. (2009).

11. McCartney J.S. \& Murphy, K.D. Strain distributions in full-scale energy foundations. DFI Journal. 6(2), 26-38. (2012).

12. Akrouch G., Sánchez, M., and Briaud, J.L. Thermomechanical behavior of energy piles in high plasticity clays Acta Geotechnica. - 9(3): 399-412, (2014).

13. Mimouni T. \& Laloui, L. Towards a secure basis for the design of geoenergy piles: Acta Geotechnica 9(3), 355-366, (2014).

14. Wang B., Bouazza, A., Singh, R.M., Haberfield, C., Barry-Macaulay, D. \& Baycan, S. Posttemperature effects on shaft capacity of a full-scale geothermal energy pile Geotech. Geoenviron. Eng. 4, 04014125 (2014).

15. Murphy K.D., McCartney, J.S. \& Henry, K.S. Evaluation of thermo-mechanical and thermal behavior of full-scale energy foundations: Acta
Geotechnica. Acta Geotechnica. 10(2), 179-195, (2015).

16. Sutman M., Olgun, C. G., \& Laloui, L. Cyclic loadtransfer approach for the analysis of energy piles. Journal of Geotechnical and Geoenvironmental Engineering. 145(1) (2015).

17. McCartney J.S. and Murphy, K.D. Investigation of potential dragdown/uplift effects on energy piles. Geomechanics for Energy and the Environment. 10(June), 21-28. (2017).

18. Di Donna A., Ferrari, A. \& Laloui, L. Experimental investigation of the soil concrete interface: physical mechanisms, cyclic mobilization and behavior at different temperatures: Can. Geotech., 53(4), 659672. (2016).

19. McCartney J.S. \& Rosenberg J.E. Impact of heat exchange on the axial capacity of thermo-active foundations. Proceedings of Geo-Frontiers 2011 (GSP 211). J. Han and D.E. Alzamora, eds. ASCE, Reston VA. pp. 488-498. (2011).

20. Ng, C. W. W., Shi, C., Gunawan, A., and Laloui, L. (2014). "Centrifuge modelling of energy piles subjected to heating and cooling cycles in clay." Geotechnique Lett., 4(4), 310-316.

21. Stewart, M.A. and McCartney, J.S. (2014). Centrifuge modeling of soil-structure interaction in energy foundations. ASCE Journal of Geotechnical and Geoenvironmental Engineering. 140(4), 04013044-1-11.

22. Goode, J.C., III and McCartney, J.S. (2015). Centrifuge modeling of boundary restraint effects in energy foundations. Journal of Geotechnical and Geoenvironmental Engineering. 141(8), 04015034. DOI: 10.1061/(ASCE)GT.1943-5606.0001333.

23. Ferreira M.S., Estacas geotérmicas: uso de energia sustentável e resposta termomecânica sob variação de temperatura. Disseratação de Mestrado. (2017).

24. Laloui L. \& Cekerevac C. Thermo-plasticity of clays: an isotropic yield mechanism: Computers and Geotechnics, 30(8):649-660. (2003).

25. Di Donna A. \& Laloui, L. Advancements in the geotechnical design of energy piles. Proceedings of International Workshop on Geomechanics and Energy. 26-28. (2013).

26. Di Donna A. \& Laloui, L. Numerical analysis of the geotechnical behaviour of energy piles Int. J. Numer. Analyt. Methods Geomech. 39(8): 861-888. (2015)

27. Yavari N., Tang, A. M., Pereira, J.M. \& Hassen, G. Effect of temperature on the shear shear strength of soils and soil/ structure interface. Can. Geotech. J. 53(7): 1186-1194 (2016). 